\title{
Eine Richterzeitung - braucht es das überhaupt?
}

Wozu brauchen denn Richterinnen und Richter bloss eine eigene - immerhin digitale - Zeitung? Und gibt es überhaupt genügend interessierte Leserinnen und Leser, die so etwas finanzieren? Findet man da Autorinnen und Autoren, die mitschreiben? Und wie baue ich da ein Netz von Letzteren auf? Höchstwahrscheinlich sind wir damals als Verlag vor 15 Jahren die Geschichte deutlich optimistischer und offener angegangen, als es die paar Einstiegsfragen vermuten lassen, aber zumindest ich als damaliger Verlagsleiter habe mir insgeheim auch ein paar kritische Fragen gestellt.

Beitragsart: Jubiläum

Zitiervorschlag: Nils Güggi, Eine Richterzeitung - braucht es das überhaupt?, in: «Justice - Justiz - Giustizia» 2020/4 
[1] Das damalige Gründungs-Redaktionsteam hat im Jahr 2005 die Antwort auf die erste Frage in ihrem allerersten Editorial gleich selber gegeben: «Richterinnen und Richter, Staatsanwältinnen und Staatsanwälte, Gerichtsschreiberinnen und Gerichtsschreiber brauchen eine für jede und jeden von ihnen offen stehende Zeitschrift. Sie brauchen eine Stimme in der Justizöffentlichkeit und in der politischen Öffentlichkeit. Sie brauchen ein Forum des Austausches, der Information, der Kritik, der Vision.»

[2] Soweit so gut, die Schweizerische Vereinigung der Richterinnen und Richter SVR hatte beschlossen, das Projekt zu unterstützen, was sehr erfreulich und wichtig war. Das damalige Redaktionsteam befand sich zwar noch in der Gründungsphase, es wurde aber schnell deutlich, dass diese Persönlichkeiten sich stark für die Richterzeitung engagierten und entweder selber schreiben würden oder dann aber über ein grosses Netzwerk verfügten, in welchem sie sich bewegten und wo sie Autorinnen und Autoren rekrutieren konnten.

[3] Nun stellte sich eigentlich nur noch die Frage danach, ob der Fokus auf Richterinnen und Richter, Staatsanwältinnen und Staatsanwälte, Gerichtsschreiberinnen und Gerichtsschreiber genügend Inhalte hergeben konnte. Aus heutiger Optik - und für Sie als Leserinnen und Leser - mag die Frage naiv klingen, aber für mich war die Frage auch eine nach der künftigen potentiellen Qualität und Rentabilität der Richterzeitung. Ich war damals Leiter von Jusletter und im Übergang zum Verlagsleiter. Als solcher musste ich mich mit den visionären Gedanken der Weblaw-Gründer Franz Kummer und Sarah Montani auseinandersetzen, mit ihnen zusammen aber auch zu einer realistischen Prognose kommen. War es eine potentiell länger offene Baustelle und Ressourcengrab oder ein Superding?

[4] Heute sieht die Sache klarer aus. 60 Ausgaben wurden veröffentlicht, die hier vorliegende Ausgabe ist die Nr. 61. Die Richterzeitung ist 15 Jahre alt geworden. Nach den ersten paar Jahren durfte ich sie an Daniel Hürlimann übergeben, der heute Professor ist. Fünf Jahre später habe ich die Weblaw AG verlassen und bin in die Bundesverwaltung gewechselt.

[5] Ich gebe zu, seither habe ich die Richterzeitung etwas aus den Augen verloren. Wenn ich jetzt so den digitalen Lebenslauf der Richterzeitung anschaue, muss ich zugeben, dass sie sich ziemlich gut entwickelt hat. Sie hat ganz offensichtlich ihr Zielpublikum gefunden und stösst auf den verdienten Anklang. Damit dürfte sie wohl auch ihre Kosten decken, was für Verlagsprodukte im juristischen Bereich nicht selbstverständlich ist. Schliesslich zeigt ein digitaler Streifzug über die Ausgaben der letzten Jahre auch ein klares inhaltliches Profil. Es fägt, sie zu lesen. Der Fokus ist klar.

[6] Nebst dem finanziellen Aspekt und dem Zielpublikum finde ich persönlich aber zunehmend einen dritten Punkt immer augenfälliger: Richterinnen und Richter, Staatsanwältinnen und Staatsanwälte und überhaupt das Justizpersonal brauchen ein Publikationsorgan, brauchen die wissenschaftliche Auseinandersetzung mit ihren Fragen, brauchen diese klare Stimme. Einmal mehr zeigt uns die Politik, dass die Unabhängigkeit der Justiz - und dazu gehören auch einzelne Personen, die in der Justiz ihre Rolle haben - nicht einfach so gegeben und etwas Selbstverständliches ist. Man muss die Unabhängigkeit der Justiz diskutieren, entwickeln und für sie kämpfen. Man muss sich gegen Relativierungen wehren. Ohne sie kann sich die Schweiz als Rechtsstaat nicht behaupten. Auch dafür ist diese Schweizer Richterzeitung nötig und wichtig.

[7] Darum freue ich mich auf die nächsten 15 Jahre Schweizer Richterzeitung!

[8] PS: Eine kleine kritische Note zuhanden der Justiz sei mir verziehen: Eine unabhängige, selbstbewusste Justiz hat nichts zu verstecken. Auch die Transparenz der Justiz ist gesellschaftlich 
wichtig. Urteile aller Instanzen in der Schweiz gehören ausnahmslos und anonymisiert veröffentlicht. Medienschaffenden ist unter gewissen Bedingungen ein privilegierter Zugang zu geben. Und auch alle (!) Strafbefehle sollten schweizweit mindestens den Medienschaffenden digital zugänglich gemacht werden.

Nils GügGI, lic.iur., Executive MBA, war von 2000-2010 in verschiedenen Funktionen für die Weblaw AG tätig, zuletzt als Verlagsleiter. Seit Ende 2010 arbeitet er für den im EJPD angesiedelten Dienst Überwachung Post- und Fernmeldeverkehr (Dienst ÜPF), seit 2014 als Bereichsleiter Recht und Controlling und Mitglied der Geschäftsleitung des Dienstes ÜPF. Auf Twitter ist er zu finden unter https://twitter.com/Nils_Gueggi.

Der Autor vertritt in diesem Beitrag seine persönliche Meinung. 